\title{
Impact of Bioactive Glass-Based Toothpaste on Color Properties and Surface Microhardness of Bleached Enamel
}

\author{
Raíssa Manoel Garcia ${ }^{1}$ Waldemir Francisco Vieira-Junior ${ }^{1,2}$ Jéssica Dias Theobaldo ${ }^{1}$ \\ Flávio Henrique Baggio Aguiar ${ }^{1}$ Débora Alves Nunes Leite Lima ${ }^{1}$
}

\author{
${ }^{1}$ Department of Restorative Dentistry, Piracicaba Dental School, \\ University of Campinas - Unicamp, Piracicaba, SP, Brazil \\ ${ }^{2}$ Department of Restorative Dentistry, São Leopoldo Mandic \\ Institute and Dental Research Center, Campinas, SP, Brazil
}

\begin{abstract}
Address for correspondence Waldemir Francisco Vieira Junior, DDS, MSc, PhD, São Leopoldo Mandic Institute and Dental Research Center, Rua José Rocha Junqueira, 13 - CEP 13045-755, Campinas, SP, Brazil (e-mail: waldemir.f@hotmail.com,waldemir.junior@ slmandic.edu.br).
\end{abstract}

Eur J Gen Dent 2021;10:1-6.

\begin{abstract}
Keywords

- hydrogen peroxide

- surface properties

- tooth bleaching

- tooth bleaching agents

Objective The role of toothpaste used during aesthetic treatments is rarely investigated. The objective was to evaluate the effects of a bioactive glass-based toothpaste (BGT) used before or after the dental bleaching with $35 \%$ hydrogen peroxide (HP).

Materials and Methods Bovine enamel blocks $(4 \times 4 \mathrm{~mm} ; n=12)$ were submitted to tooth bleaching and different treatments/storage, before or after HP, based on: (1) no toothpaste and immersion in artificial saliva (AS) after HP for 24 hours, 7 days, or 14 days (control); (2) daily BGT use and AS storage for 7 or 14 days (after HP); and (3) daily BGT use and AS storage for 7 or 14 days (prior to HP). Surface and in-depth color were determined using the $\mathrm{CIE} \mathrm{L}^{*} \mathrm{a}^{*} \mathrm{~b}^{*}$ system $\left(\Delta \mathrm{L}^{*}, \Delta \mathrm{a}^{*}, \Delta \mathrm{b}^{*}\right.$, and $\left.\Delta \mathrm{E}\right)$ on enamel surface and underlying dentin. The surface microhardness (SMH) was evaluated using a Knoop microhardness tester.

Statistical Analysis Data were submitted to analysis of variance (ANOVA) (color variables), repeated measures ANOVA (SMH), and Tukey's test $(\alpha=0.05)$.

Results The color changes on the enamel or underlying dentin were not statistically different among the groups $(p>0.05)$. Twenty-four hours after HP presented a decrease in SMH differing from baseline $(p<0.01)$. This decrease did not occur in the groups previously exposed to BGT $(p>0.05)$. BGT use after HP for 7 days differed from group with exclusive AS storage $(p<0.05)$.

Conclusion In-office tooth bleaching can decrease the microhardness of enamel surface; however, the use of BGT promotes the protection or enables the mineral recovery of tooth without the influence the bleaching efficacy.
\end{abstract}

\section{Introduction}

The dissemination of aesthetic dentistry and the demand for a harmonious smile are increasingly common nowadays.
Among the dental treatments available, dental bleaching treats stained teeth by making them lighter and less yellow by using bleaching agents such as hydrogen peroxide (HP), ${ }^{1,2}$ which is an oxidizing agent with a low molecular weight
DOI https://doi.org/ $10.1055 / \mathrm{s}-0041-1732773$ ISSN 2320-4753 (c) 2021. European Journal of General Dentistry.

This is an open access article published by Thieme under the terms of the Creative Commons Attribution-NonDerivative-NonCommercial-License, permitting copying and reproduction so long as the original work is given appropriate credit. Contents may not be used for commercial purposes, or adapted, remixed, transformed or built upon. (https://creativecommons.org/licenses/by-nc-nd/4.0/). Thieme Medical and Scientific Publishers Pvt. Ltd. A-12, 2nd Floor, Sector 2, Noida-201301 UP, India 
that dynamically diffuses through the dental structure due to its chemical affinity for mineralized tissues. ${ }^{3,4} \mathrm{HP}$ reacts especially to dentin ${ }^{5}$ through organic chromophores, which are responsible for changing in tooth color. Free radicals prompt an oxidation-reduction reaction to force this change. Compared with the original stain molecule, ${ }^{6}$ which can be easier to remove from a dental structure, these reaction products are more polar and lower in molecular weight, qualities that decrease the absorption of light. ${ }^{7}$

Dental bleaching is currently considered a predictable and safe treatment when clinically indicated appropriately. ${ }^{7,8}$ Nevertheless, HP could result in adverse changes on the teeth, such as the alteration of the mineral content and chemical properties of dental hard tissues. ${ }^{9-16}$ Compounds based on fluoride, ${ }^{17,18}$ arginine, ${ }^{19}$ nano-hydroxyapatite, ${ }^{20}$ or bioactive glass ${ }^{21-23}$ were described to decrease the adverse effects from bleaching procedures.

Bioactive glass was initially reported to stimulate bone regeneration and is currently used in oral care for treatment of dentin hypersensitivity..$^{24,25}$ This bioactive material, when in contact with saliva or body fluids can stimulate the supply of calcium, phosphate, and sodium, ${ }^{25}$ precipitating a hydroxycarbonate apatite layer. ${ }^{25,26}$ Moreover, bioactive glass products seem to protect the enamel against the mineral dissolution caused by HP gels when applied prior to in-office tooth bleaching, ${ }^{22,23}$ demonstrate antierosive potential, ${ }^{26}$ and reduce the HP diffusion into pulp chambers. ${ }^{27}$

The effect of different toothpastes on the properties of a bleached tooth is rarely discussed. The study of this relationship is relevant because the use of toothpastes, whether one composed with conventional fluoride or bioactive glass, is trivial for the patient and often not guided by recommendation of dentist. The investigation of the best time to use this compound, the effects of other times of frequency of use, and the in-depth bleaching effectiveness of the underlying dentin and HP diffusion are unclear.

The objective of the present in vitro study was to investigate the effect of bioactive glass-based toothpaste (BGT), used prior to or after dental bleaching for 1 or 2 weeks, on the surface microhardness (SMH) of enamel and tooth color. The null hypotheses tested were that (1) the in-office dental bleaching would not affect the SMH and that (2) the BGT would not affect the SMH or bleaching efficacy when associated to in-office dental bleaching therapy.

\section{Materials and Methods}

\section{Sample Preparation}

Bovine teeth were collected and stored in a $0.1 \%$ thymol solution. Samples with a $16-\mathrm{mm}^{2}$ surface area $(4 \times 4 \mathrm{~mm})$ and 2-mm thickness ( $1 \mathrm{~mm}$ of enamel and $1 \mathrm{~mm}$ of dentin) were obtained from the buccal surface of the bovine incisive crowns. The sectional cut of the teeth was performed using a high-precision diamond disc (Buehler, Lake Bluff, Illinois, United States) coupled with a precision cutting machine (Isomet 1000, Buehler). The sectioned blocks were planed and polished with a series of 1200-, 2400-, and 4000-grit paper using a water-cooled polishing machine (Aropol 2V,
Arotec, Cotia, SP, Brazil) followed by polishing cloths and a 1.0-, 0.5-, or 0.25- $\mu \mathrm{m}$ diamond spray (Buehler). Afterwards, the samples were immersed in deionized water in an ultrasonic machine (Marconi, Piracicaba, SP, Brazil) for 15 minutes among the sandpapers and cloths to remove residue in the polishing processes. Allocation of the samples to the groups was performed by stratification considering the values of $\mathrm{L}^{*}$, which provides low variation in the baseline color values of the groups. The description of SMH analysis and color coordinate measurements will be reported later in more detail.

\section{Experimental Groups, Toothpaste Treatment, and Bleaching Procedure}

The samples $(n=12)$ were randomly submitted to in vitro treatments varying in BGT exposure, time of BGT use (before or after), and bleaching procedure, as described below:

The following groups were subjected to different treatments after 35\% HP, with analyses performed at baseline, 24 hours, 7 days, and 14 days after dental bleaching:

HP and artificial saliva (AS): The samples endured a bleaching procedure with $35 \% \mathrm{HP}$, had no pre- or postuse of toothpaste, and were immersed in AS solution for all experiment.

The samples submitted to the bleaching procedure with $35 \%$ HP, without pre- or postuse of toothpaste, and were immersed in an AS solution for 24 hours after HP exposure were considered the control group.

HP and BGT: The samples were subjected to the use of a BGT twice a day 24 hours after 35\% HP and were immersed in an AS solution for all experiment.

Similar to the previous groups, samples in the remaining two groups all underwent a dental bleaching procedure with 35\% HP and were analyzed for their SMH and color at either baseline or 24 hours after the bleaching procedure; they, however, received BGT treatment before the bleaching procedure rather than after:

BGT ( 7 days) and HP: The samples were treated with BGT twice a day for 7 days and were immersed in an AS solution when not exposed to BGT.

BGT (14 days) and HP: The samples were treated with BGT twice a day for 14 days and were immersed in an AS solution for the remainder of the experiment.

The bleaching procedure was performed with 35\% HP (Whiteness HP, FGM, Joinville, SC, Brazil). This bleaching gel was applied three times on the enamel surface of the sample for 15 minutes for each application, in accordance to the manufacturer's instructions. The samples in the toothpaste groups were exposed to commercial toothpaste containing bioactive glass (Sensodyne Repair \& Protect, GlaxoSmithKline, Berkshire, United Kingdom). For this, the samples were submitted to contact with toothpaste slurry twice a day according to the manufacturer's recommendations. The slurry was composed of toothpaste and AS (1:3 ratio by weight), ${ }^{28}$ and the samples were immersed in $2.5 \mathrm{~mL}$ of the slurry, twice daily for 2 minutes in each exposure in constant and controlled agitation. ${ }^{28}$ At the end of this step, the samples were washed with deionized water and individually immersed in AS until the next cycle. The AS is represented by a remineralizing solution ${ }^{29}$ renewed every day during the experiment. 
Information about the bleaching gel, toothpaste, and remineralizing solution (AS) is detailed in - Table 1.

\section{Color Measurements}

The color analysis of each sample was performed in daylight in a standardized ambient light condition (GTI MiniMatcher MM 1, GTI Graphic Technology, New York, United States). The color coordinates was determined using a reflectance spectrophotometer (CM 700d, Minolta, Osaka, Japan). The spectral distribution was established based on the CIE L*a*b* system $\left(L^{*}, a^{*}, b^{*}\right.$, and $\left.\Delta E\right)$. The variation in final and initial values was represented by the $\Delta$ coordinate $\left(\Delta \mathrm{L}^{*}, \Delta \mathrm{a}^{*}\right.$, and $\left.\Delta \mathrm{b}^{*}\right)$. The general color alteration was expressed by $\Delta \mathrm{E}=\left[\left(\Delta \mathrm{L}^{*}\right)^{2}+\left(\Delta \mathrm{a}^{*}\right)^{2}\right.$ $\left.+\left(\Delta \mathrm{b}^{*}\right)^{2}\right]^{1 / 2}$. The measurements were conducted before and after the 35\% HP dental bleaching on the enamel surface and underlying dentin. The evaluation of underlying dentin was performed to evaluate the bleaching efficacy in depth.

\section{Surface Microhardness Analysis}

The SMH analysis was performed in a microhardness tester (Shimadzu HMV-2000, Tokyo, Japan) using a Knoop indenter with a load of $50 \times g$ and time of 5 seconds. Five indentations were made in the central region of each sample with $100 \mu \mathrm{m}$ of distance between each indentation. The SMH value was obtained through an arithmetic mean of the five indentations.

\section{Statistical Analysis}

After the exploratory analysis, the enamel color variables $\left(\Delta \mathrm{L}^{*}, \Delta \mathrm{a}^{*}, \Delta \mathrm{b}^{*}\right.$, and $\left.\Delta \mathrm{E}\right)$ and underlying dentin $\left(\Delta \mathrm{a}^{*}, \Delta \mathrm{b}^{*}\right.$, and $\Delta \mathrm{E}$ ) were submitted to analysis of variance and Tukey's test. The $\Delta \mathrm{L}^{*}$ results of the underlying dentin did not presuppose the data normality and were evaluated by the Kruskal-Wallis test. The data of SMH were evaluated by repeated measurements mixed procedure (PROC MIXED) and Tukey-Kramer using the SAS software (SAS Institute Inc. 2016, Cary, North Carolina, United States). The level of significance for all analyses was set at 0.05 .

Table 1 Description of products including manufacturers and composition

\begin{tabular}{|c|c|}
\hline $\begin{array}{l}\text { Product } \\
\text { (Manufacturer) }\end{array}$ & Composition \\
\hline $\begin{array}{l}\text { Whiteness HP: } \\
\text { 35\% hydrogen } \\
\text { peroxide gel } \\
\text { (FGM, Joinville, } \\
\text { Brazil) }\end{array}$ & $\begin{array}{l}\text { 35\% hydrogen peroxide, thickener } \\
\text { (Carbopol), glycol, water }\end{array}$ \\
\hline $\begin{array}{l}\text { Sensodyne } \\
\text { Repair \& Protect: } \\
\text { Novamin } \\
\text { Technology } \\
\text { (GlaxoSmithKline, } \\
\text { Berkshire, United } \\
\text { Kingdom) }\end{array}$ & $\begin{array}{l}\text { 5\% calcium sodium phosphosilicate, sodium } \\
\text { monofluorophosphate (MFP) - } 1426 \text { ppm, } \\
\text { glycerin, silica, PEG-8, titanium dioxide, } \\
\text { carbomer, cocamidopropyl betaine, sodium } \\
\text { methyl cocoyl taurate, sodium saccharin, } \\
\text { D-limonene }\end{array}$ \\
\hline $\begin{array}{l}\text { Remineralizing } \\
\text { solution } \\
\text { (artificial saliva) }\end{array}$ & $\begin{array}{l}1.5 \mathrm{mM} \mathrm{Ca}, 0.9 \mathrm{mM} \text { P, } 150 \mathrm{mM} \mathrm{KCL}, 0.05 \mu \mathrm{g} \\
\mathrm{F} / \mathrm{mL} \text {, and } 0.1 \mathrm{M} \text { Tris buffer, set to a } \mathrm{pH}=7\end{array}$ \\
\hline
\end{tabular}

\section{Results}

The results of the color analysis for enamel surface are indicated in - Table 2. For enamel, the $\Delta \mathrm{L}^{*}, \Delta \mathrm{a}^{*}, \Delta \mathrm{b}^{*}$, and $\Delta \mathrm{E}$ values did not show statistical differences between the groups $(p>0.05)$. The color analysis results for underlying dentin are presented in - Table 3 . The values $\Delta \mathrm{L}^{*}, \Delta \mathrm{a}^{*}$, and $\Delta \mathrm{E}$ did not differ statistically between the groups. For the $\Delta \mathrm{b}^{*}$ values for underlying dentin, AS (14 days) was statistically different $(p<0.0001)$ from the analysis performed 24 hours after dental bleaching.

Moreover, AS (14 days) was different from the groups subjected to BGT for 7 or 14 days prior to 35\% HP exposure. However, no difference was found between these groups and the other groups exposed to AS or AS + BGT $(p>0.05)$. All groups that were submitted to in-office dental bleaching demonstrated an increase in the $\mathrm{L}^{*}$ values (positive means) and $a$ decrease in the $b^{*}$ values (negative means) independently of tooth substrate, toothpaste treatment, or storage condition.

For the SMH values ( - Table 4 ), an effect was found in the following factors: time $(p<0.0001)$, toothpaste exposure or storage condition ( $p=0.0178)$, and interaction of the factors $(p=0.0005)$. The baseline results for the groups were not statistically different $(p>0.05)$. After dental bleaching (24 hours), AS and AS + BGT presented a decrease in SMH values compared with baseline values $(p<0.01)$. For 24 hours after HP the group of BGT prior to $35 \%$ HP for 7 days presented SMH values significantly higher than the AS and AS + BGT groups (after 35\% HP). For AS, the SMH values after 7 days did not statistically differ from baseline or after 24 hours $(p>0.05)$. The SMH values were reestablished after 14 days, where no differences were found comparing to the baseline values $(p>0.05)$, differing from a 24-hour period after HP $(p<0.01)$. For AS + BGT, the SMH values after 7 days did not statistically differ from baseline but instead differed from the values found after 24 hours ( $p<0.05$ ). Furthermore, these values were higher and statistically different from the correlated AS group not exposed to BGT $(p<0.01)$. After 14 days, the SMH values of the AS + BGT group were higher and statistically different from baseline values $(p<0.05)$. The decrease in SMH values was not found in groups exposed to BGT prior to dental bleaching. A decrease in SMH values after dental bleaching did not occur in groups previously exposed to BGT, which obtained results similar to the baseline values and were statistically different $(p<0.01)$ from values described for after dental bleaching ( 24 hours).

\section{Discussion}

Based on the results of this experiment, the first null hypothesis was rejected; a decrease in values for enamel microhardness was found 24 hours after the in-office dental bleaching. Nevertheless, the results fail to reject the second null hypothesis because the groups exposed to daily use of BGT obtained enamel protection against alterations in physical properties or a mineral recovery superior to the AS immersion only without the influence of the bleaching efficacy of treatment. 
Table 2 Mean (SD) for $\Delta \mathrm{L}^{*}, \Delta \mathrm{a}^{*}, \Delta \mathrm{b}^{*}$, and $\Delta \mathrm{E}$ on enamel surfacea

\begin{tabular}{|c|c|c|c|c|}
\hline & \multicolumn{4}{|c|}{ Enamel surface } \\
\hline & $\Delta \mathrm{L}^{*}$ & $\Delta \mathrm{a}^{*}$ & $\Delta \mathrm{b}^{*}$ & $\Delta \mathrm{E}$ \\
\hline \multicolumn{5}{|l|}{ After 35\% HP } \\
\hline AS (24 h) & $2.88(1.04)^{\mathrm{a}}$ & $-0.20(0.31)^{\mathrm{a}}$ & $-4.51(0.74)^{a}$ & $5.44(0.92)^{\mathrm{a}}$ \\
\hline AS (7d) & $2.83(1.06)^{\mathrm{a}}$ & $-0.47(0.28)^{a}$ & $-4.23(0.86)^{a}$ & $5.20(1.04)^{a}$ \\
\hline AS (14d) & $2.27(0.87)^{\mathrm{a}}$ & $-0.08(0.45)^{\mathrm{a}}$ & $-3.13(1.36)^{\mathrm{a}}$ & $4.35(2.21)^{\mathrm{a}}$ \\
\hline$A S+B G T(7 d)$ & $2.84(1.38)^{\mathrm{a}}$ & $-0.31(0.27)^{\mathrm{a}}$ & $-4.02(1.27)^{\mathrm{a}}$ & $4.98(1.73)^{\mathrm{a}}$ \\
\hline$A S+B G T(14 d)$ & $2.37(1.53)^{\mathrm{a}}$ & $-0.17(0.26)^{\mathrm{a}}$ & $-3.90(1.31)^{\mathrm{a}}$ & $4.57(1.85)^{\mathrm{a}}$ \\
\hline \multicolumn{5}{|l|}{ BGT prior to $35 \% \mathrm{HP}$} \\
\hline $7 \mathrm{~d}$ & $3.81(1.62)^{\mathrm{a}}$ & $-0.51(0.45)^{\mathrm{a}}$ & $-4.85(2.61)^{a}$ & $6.82(3.35)^{\mathrm{a}}$ \\
\hline $14 \mathrm{~d}$ & $3.74(1.69)^{\mathrm{a}}$ & $-0.13(0.77)^{\mathrm{a}}$ & $-4.83(2.49)^{a}$ & $6.08(2.49)^{\mathrm{a}}$ \\
\hline
\end{tabular}

Abbreviations: AS, artificial saliva; BGT, bioactive glass-based toothpaste; HP, hydrogen peroxide; SD, standard deviation.

adentical lowercase letters indicate no significant difference $(p>0.05)$ among different groups in the same column.

Table 3 Mean (SD) for $\Delta \mathrm{L}^{*}, \Delta \mathrm{a}^{*}, \Delta \mathrm{b}^{*}$, and $\Delta \mathrm{E}$ on underlying dentin (in-depth color)a

\begin{tabular}{|l|l|l|l|l|}
\hline & \multicolumn{5}{|c|}{ Underlying dentin } & $\Delta \mathrm{E}$ \\
\hline After 35\% HP & $\Delta \mathrm{L}^{*}$ & $\Delta \mathrm{a}^{*}$ & & \\
\hline AS (24 h) & & & $-1.44(1.13)^{\mathrm{bc}}$ & $2.46(1.28)^{\mathrm{a}}$ \\
\hline AS (7 d) & $1.75(1.08)^{\mathrm{a}}$ & $0.10(0.43)^{\mathrm{a}}$ & $-1.07(1.09)^{\mathrm{abc}}$ & $2.29(1.12)^{\mathrm{a}}$ \\
\hline AS (14 d) & $1.76(0.89)^{\mathrm{a}}$ & $-0.37(0.46)^{\mathrm{a}}$ & $0.79(1.06)^{\mathrm{a}}$ & $2.05(0.84)^{\mathrm{a}}$ \\
\hline AS+BGT (7 d) & $1.17(1.28)^{\mathrm{a}}$ & $0.05(0.43)^{\mathrm{a}}$ & $-0.85(1.64)^{\mathrm{ab}}$ & $2.60(1.35)^{\mathrm{a}}$ \\
\hline AS+BGT (14 d) & $2.07(1.12)^{\mathrm{a}}$ & $-0.36(0.50)^{\mathrm{a}}$ & $-0.75(1.59)^{\mathrm{ab}}$ & $2.83(2.10)^{\mathrm{a}}$ \\
\hline BGT prior to 35\% HP & $2.17(2.25)^{\mathrm{a}}$ & $-0.29(0.45)^{\mathrm{a}}$ & & $4.39(2.52)^{\mathrm{a}}$ \\
\hline 7 d & & & $-2.82(2.42)^{\mathrm{bc}}$ & $3.84(2.29)^{\mathrm{a}}$ \\
\hline 14 d & $3.14(1.93)^{\mathrm{a}}$ & $-0.36(0.83)^{\mathrm{a}}$ & $-3.12(2.24)^{\mathrm{c}}$ & \\
\hline
\end{tabular}

Abbreviations: AS, artificial saliva; BGT, bioactive glass-based toothpaste; HP, hydrogen peroxide; SD, standard deviation.

aldentical lowercase letters indicate no significant difference $(p>0.05)$ among different groups in the same column.

Table 4 Mean (SD) for surface microhardness (SMH) based on treatment group at different timea

\begin{tabular}{|l|l|l|l|l|}
\hline & \multicolumn{3}{|c|}{ After 35\% HP } \\
\hline & Baseline & $24 \mathrm{~h}$ & $7 \mathrm{~d}$ & $\mathbf{1 4}$ \\
\hline AS & $282.8(31.7)^{\mathrm{ABa}}$ & $221.8(41.7)^{\mathrm{Cc}}$ & $252.1(44.1)^{\mathrm{BCb}}$ & $293.6(45.5)^{\mathrm{Aa}}$ \\
\hline AS+BGT & $286.8(34.2)^{\mathrm{Ba}}$ & $252.0(24.7)^{\mathrm{Cbc}}$ & $314.0(28.7)^{\mathrm{Aa}}$ & $330.3(19.6)^{\mathrm{Aa}}$ \\
\hline BGT prior to 35\% HP & & & & - \\
\hline 7 d & $284.1(33.7)^{\mathrm{Ba}}$ & $321.5(29.1)^{\mathrm{Aa}}$ & - & - \\
\hline 14 d & $285.4(14.1)^{\mathrm{Aa}}$ & $293.4(33.2)^{\mathrm{Aab}}$ & - & - \\
\hline
\end{tabular}

Abbreviations: AS, artificial saliva; BGT, bioactive glass-based toothpaste; HP, hydrogen peroxide; SD, standard deviation.

${ }^{a}$ Means followed by different letters (uppercase in rows and lowercase in columns) are different $(p<0.05)$.

Moreover, the microhardness change was not observed in the samples treated with BGT for 7 days before dental bleaching obtaining SMH results similar to those of unbleached enamel.

Dental enamel is characterized by extreme hardness, but it can be altered in demineralizing events, releasing calcium or phosphorus by hydroxyapatite crystal. ${ }^{15,23}$ Enamel is a highly mineralized and crystalline hard tissue with a certain permeability that allows the diffusion of substances and ionic exchanges within the oral environment.
These characteristics enable the diffusion of HP through the dental structure during dental bleaching. ${ }^{6}$ When correctly indicated, tooth bleaching is considered an effective and safe treatment. ${ }^{1,2,7,8}$

$\mathrm{HP}$, the active ingredient in bleaching gels, ${ }^{2}$ is an oxidizing agent that diffuses freely through the enamel to the dentin. This diffusion is favored due to the low molecular weight of HP and its byproducts, which facilitate the course of this molecule through mineralized dental tissues. ${ }^{3} \mathrm{HP}$, as an 
oxidizing agent, breaks down the pigment molecules, leaving them small enough to be removed from the dental structure through diffusion, which indirectly promotes the reduction of light absorption. ${ }^{6,30}$ In the present study, the application of bleaching gel demonstrated efficacy and the toothpaste used did not interfere in the bleaching process. The following results demonstrated a significant change in the lightness and general color of the teeth samples: reduction of $\mathrm{b}^{*}$ values (negative $\mathrm{b}^{*}$ value), increase in $\mathrm{L}^{*}$ values (positive $L^{*}$ values), and mean values of total color change $(\Delta E)$ to be higher than 4.2 units, which Alghazali et $\mathrm{al}^{31}$ suggested as clinical acceptability of color difference. In the current study, the color assessment of the underlying dentin is important because it indicates indirectly the bleaching efficacy in depth associated with HP penetration and diffusion. ${ }^{32}$ The toothpaste treatment did not demonstrate relevant differences related to surface or in-depth color analyses comparing to control protocol (AS).

Regardless, the HP acted on the mineral and organic content of dental structure. HP is commonly presented in products with an acidic $\mathrm{pH}^{33}$ which could potentiate the mineral loss or more significant erosion of enamel. ${ }^{34}$ Thus, HP can affect the physicochemical properties of dental structures $^{9-16}$; managements and actives were described in the literature as ways to minimize damage to teeth provoked by bleaching agents. Among these actives, the bioactive glass has been indicated due to its high bioactivity and beneficial properties. $^{22,23,35}$

The bioactive glass (45S5), proposed by Hench et $\mathrm{al}^{36}$ is used in different areas, and commercially available through the toothpaste by NovaMin technology. In the present study, the BGT demonstrated a potential benefit in reducing the adverse effect of tooth bleaching on SMH without influencing bleaching efficacy. The groups submitted to BGT use prior to tooth bleaching presented SMH values similar to baseline (sound enamel), indicating the presence of a surface protectant that decreases the effects during demineralizing event associated to dental bleaching. Tooth brushing is crucial in routine hygiene habits, the present study employed a practical, suitable regime for dental bleaching without adding new clinical steps. ${ }^{37}$

Considering the use of bioactive glass (NovaMin), previous studies $^{22,23}$ suggested that simulated brushing for 1 month decreases the mineral loss of enamel that a bleaching procedure could promote. The present investigation indicates that even just using the toothpaste for 1 week before the bleaching procedure would be enough to replicate these results. Bioactive glass is a biomaterial ${ }^{36}$ composed of sodium calcium phosphosilicate, which in aqueous media provides a rich environment in calcium and phosphate ions, ${ }^{25}$ forming a carbonated hydroxyapatite layer that is chemically similar to the natural apatite of the tooth and reservoir of relevant ions for remineralization.

Deng et $\mathrm{al}^{21}$ reported that bioactive glass could form a protective layer on the enamel surface to inhibit demineralization or enhance remineralization. This mechanism explained the beneficial results of a BGT in the present study. On the other hand, the use of the toothpaste for 7 days prior to a bleaching treatment appears to be more important in protecting an eventual mineral loss provoked by an HP gel than to use it as a remineralizing agent after in-office teeth bleaching to repair any damage to the tissues. In the present study, the AS is represented by a remineralizing solution that is able to promote the mineral recovery of dental hard tissues. After 14 days, the samples exposed only to the AS also obtained recovery of the initial microhardness values. Therefore, in vitro studies are important precursors for the advancement of clinical management, and future in vivo studies may validate the findings of this study. Further studies may be conducted in the same way to procure insights regarding even safer treatments in aesthetic dentistry.

\section{Conclusion}

In-office tooth bleaching with 35\% HP decreased the enamel microhardness; however, using a BGT for 7 days strengthened the protection against the negative effect of $35 \% \mathrm{HP}$ without the influence of the bleaching efficacy.

\section{Funding}

This study was financed in part by the Coordenação de Aperfeiçoamento de Pessoal de Nível Superior - Brasil (CAPES) - Finance Code 001.

\section{Conflict of Interest}

None declared.

\section{References}

1 Kihn PW. Vital tooth whitening. Dent Clin North Am 2007;51(2):319-331, viii

2 Sulieman M. An overview of bleaching techniques: I. history, chemistry, safety and legal aspects. Dent Update 2004;31(10):608-616 doi:10.12968/denu.2004.31.10.608

3 Ontiveros JC, Paravina RD. Color change of vital teeth exposed to bleaching performed with and without supplementary light. J Dent 2009;37(11):840-847

4 Ubaldini AL, Baesso ML, Medina Neto A, Sato F, Bento AC, Pascotto RC. Hydrogen peroxide diffusion dynamics in dental tissues. J Dent Res 2013;92(7):661-665

5 Eimar H, Siciliano R, Abdallah MN, et al. Hydrogen peroxide whitens teeth by oxidizing the organic structure. J Dent 2012;40(Suppl 2) :e25-e33

6 Kwon SR, Wertz PW. Review of the mechanism of tooth whitening. J Esthet Restor Dent 2015;27(5):240-257

7 Joiner A. The bleaching of teeth: a review of the literature. J Dent 2006;34(7):412-419

8 Li Y. Safety controversies in tooth bleaching. Dent Clin North Am 2011;55(2):255-263, viii

9 Hosoya N, Honda K, lino F, Arai T. Changes in enamel surface roughness and adhesion of Streptococcus mutans to enamel after vital bleaching. J Dent 2003;31(8):543-548

10 Efeoglu N, Wood D, Efeoglu C. Microcomputerised tomography evaluation of $10 \%$ carbamide peroxide applied to enamel. J Dent 2005;33(7):561-567

11 Lee KH, Kim HI, Kim KH, Kwon YH. Mineral loss from bovine enamel by a $30 \%$ hydrogen peroxide solution. J Oral Rehabil 2006;33(3):229-233

12 Al-Salehi SK, Wood DJ, Hatton PV. The effect of $24 \mathrm{~h}$ non-stop hydrogen peroxide concentration on bovine enamel and dentine mineral content and microhardness. J Dent 2007;35(11):845-850 
13 Camargo SE, Valera MC, Camargo CH, Gasparoto Mancini MN, Menezes MM. Penetration of $38 \%$ hydrogen peroxide into the pulp chamber in bovine and human teeth submitted to office bleach technique. J Endod 2007;33(9):1074-1077

14 Abouassi T, Wolkewitz M, Hahn P. Effect of carbamide peroxide and hydrogen peroxide on enamel surface: an in vitro study. Clin Oral Investig 2011;15(5):673-680

15 Pinto A, Bridi EC, Amaral F, et al. Enamel mineral content changes after bleaching with high and low hydrogen peroxide concentrations: colorimetric spectrophotometry and total reflection X-ray fluorescence analyses. Oper Dent 2017;42(3):308-318

16 Vieira-Junior WF, Ferraz LN, Giorgi M, Ambrosano G, Aguiar F, Lima D. Effect of mouth rinse treatments on bleached enamel properties, surface morphology, and tooth color. Oper Dent 2019;44(2):178-187

17 Wiegand A, Schreier M, Attin T. Effect of different fluoridation regimes on the microhardness of bleached enamel. Oper Dent 2007;32(6):610-615

18 Cavalli V, Rodrigues LK, Paes-Leme AF, et al. Effects of the addition of fluoride and calcium to low-concentrated carbamide peroxide agents on the enamel surface and subsurface. Photomed Laser Surg 2011;29(5):319-325

19 Yesilyurt C, Sezer U, Ayar MK, Alp CK, Tasdemir T. The effect of a new calcium-based agent, Pro-Argin, on the microhardness of bleached enamel surface. Aust Dent J 2013;58(2):207-212

20 Ferraz LN, Vieira-Junior WF, Ambrosano GMB. Giorgi MCC, Aguiar FHB, Lima DANL. Effect of different concentrations of nanohydroxyapatite on tooth bleaching effectiveness and enamel bond strength. Braz Dent Sci 2018;21(1):17-25

21 Deng M, Wen HL, Dong XL, et al. Effects of $45 \mathrm{~S} 5$ bioglass on surface properties of dental enamel subjected to 35\% hydrogen peroxide. Int J Oral Sci 2013;5(2):103-110

22 Vieira-Junior WF, Lima DA, Tabchoury CP, Ambrosano GM, Aguiar FH, Lovadino JR. Effect of toothpaste application prior to dental bleaching on whitening effectiveness and enamel properties. Oper Dent 2016;41(1):E29-E38

23 Vieira-Junior WF, Ferraz LN, Pini N, et al. Effect of toothpaste use against mineral loss promoted by dental bleaching. Oper Dent 2018;43(2):190-200

24 Burwell A, Jennings D, Muscle D, Greenspan DC. NovaMin and dentin hypersensitivity-in vitro evidence of efficacy. J Clin Dent 2010;21(3):66-71
25 Jones JR. Review of bioactive glass: from Hench to hybrids. Acta Biomater 2013;9(1):4457-4486

26 Burwell AK, Litkowski LJ, Greenspan DC. Calcium sodium phosphosilicate (NovaMin): remineralization potential. Adv Dent Res 2009;21(1):35-39

27 Ma Q Chen J, Xu X, Wang T. Impact of transparent tray-based application of bioactive glasses desensitizer on the permeability of enamel and dentin to hydrogen peroxide: an in vitro study. BMC Oral Health 2020;20(1):103

28 Ganss C, Klimek J, Schlueter N. Erosion/abrasion-preventing potential of $\mathrm{NaF}$ and $\mathrm{F} / \mathrm{Sn} /$ chitosan toothpastes in dentine and impact of the organic matrix. Caries Res 2014;48(2):163-169

29 Queiroz CS, Hara AT, Paes Leme AF, Cury JA. pH-cycling models to evaluate the effect of low fluoride dentifrice on enamel deand remineralization. Braz Dent J 2008;19(1):21-27

30 Sulieman M, Addy M, Rees JS. Development and evaluation of a method in vitro to study the effectiveness of tooth bleaching. J Dent 2003;31(6):415-422

31 Alghazali N, Burnside G, Moallem M, Smith P, Preston A, Jarad FD. Assessment of perceptibility and acceptability of color difference of denture teeth. J Dent 2012;40(Suppl 1) :e10-e17

32 D'Arce MB, Lima DA, Aguiar FH, Bertoldo CE, Ambrosano GM, Lovadino JR. Effectiveness of dental bleaching in depth after using different bleaching agents. J Clin Exp Dent 2013;5(2):e100-e107

33 Price RB, Sedarous M, Hiltz GS. The $\mathrm{pH}$ of tooth-whitening products. J Can Dent Assoc 2000;66(8):421-426

34 Xu B, Li Q, Wang Y. Effects of $\mathrm{pH}$ values of hydrogen peroxide bleaching agents on enamel surface properties. Oper Dent 2011;36(5):554-562

35 Gjorgievska E, Nicholson JW. Prevention of enamel demineralization after tooth bleaching by bioactive glass incorporated into toothpaste. Aust Dent J 2011;56(2):193-200

36 Hench LL, Splinter RJ, Allen WC, et al. Bonding mechanisms at the interface of ceramic prosthetic materials. J Biomed Mater Res 1971;5(6):117-141

37 Vieira-Junior WF, Gouveia THN, Silva BG, Bueno VCPS, Aguiar FHB, Lima DANL. Toothpaste use protocol with dental bleaching for a conservative treatment: case reports. Contemp Clin Dent 2017;8(4):637-641 